\title{
Study on the Innovative Path of Governance Structure in the Perspective of Supply-side Reform
}

\author{
Lianpeng Wang ${ }^{1, \text { a }}$ \\ ${ }^{1}$ beihua university, no.3999, hua shan road, jilin city, jilin province, China \\ a278073075@qq.com
}

Keywords: Application-based undergraduate; Governance structure; Supply-side reform

\begin{abstract}
With the development of China's economy, the shortage of high-quality application-based talents is becoming more and more scarce, and the task of intellectual supply and innovation is more arduous. It has brought an unprecedented opportunity for the reform and development of application-type universities. Therefore, the supply-side on the basis of the purpose of serving the social and economic development, and targeted to do their own personnel training, technological innovation, cultural construction, institutional innovation and solve other aspects of the supply problem, and comprehensively enhance the supply capacity of the institutions.

The reform of higher education supply-side is a major reform measure proposed by the CPC Central Committee for China's current economic construction and social needs. The application colleges and universities as the backbone of personnel training, especially in the provision of scientific and technological services and front-line talent, producing significant impact on the social supply side. With the deepening reform of the supply side of higher education, the problems of application colleges and universities have gradually emerged, which seriously restricted the follow-up development of supply-side reform.
\end{abstract}

\section{The Main Problems of the Reform of the Supply Side of the Application Oriented Universities}

At present, the survey results by the authority showed that most of the application oriented colleges and universities have some common problems, that is, the purpose of running a school is unclear, the purpose of teaching become commerical, the quality of teachers is not high. In the scientific research, personnel training, social services, scientific and technological innovation and cultural heritage and other aspects, it can't meet the national talent demand standards, which leads to the application college talent supply and demand does not match the main reason.

Inefficient and homogeneous personnel training. The basic function of the application universities is to cultivate and transport talents who serve the society and enterprises to cultivate and transport talents, and should bear the primary responsibility as the source of supply for the "production end". At present, China's application universities have different degrees of problems in the professional structure, teaching quality and quality of personnel and so, and then there is a serious phenomenon of low efficiency in personnel training and homogenization.

And the homogenization of the important reason is that the autonomy of universities can't be fully protected, and the integrity of university autonomy should be composed of two parts: first, based on the respect for the law of education, respect for academic research and academic autonomy; respect for the laws of the market, independent on economic people's autonomy. Universities can't base on the school's orientation and market demand, actively and timely adjust the subject direction, professional settings, even if the actual situation to adjust, but also often experienced cumbersome expert argument, administrative examination and approval procedures, resulting in great energy of school and teachers are put into the report to fill in, and the establishment of a new professional is often the social demand that has just begun the stage, in view of the undergraduate student training cycle, who preemptively set up, the advantage of them will become more obvious. The first advantage of the small round of the ship is that the application colleges is different from other "985" "211" characteristics of the institutions, but also in line with the latest national political and political separation, management and disposal of the main 
requirements. The application of professional colleges and universities in the professional structure of personnel and professional development of the industry does not match the actual situation, and the social needs of the situation become imbalance, and the talent output homogeneity is serious, it can't take the advantages of application university personnel training; The overall structure will be lagged, which can't adapt to the development of new industries related to the application universities in the professional structure of the urgent need to address one of the outstanding contradictions. In the teaching quality, the application universities in the process of training talent, the existing comprehensive strength, knowledge structure, teaching depth, can't meet the social innovation of science and technology talent, technology development and applied talent, applied management personnel and other capabilities of comprehensive demand, not in line with social and economic restructuring and development of high-quality talent on the new requirements. China is now in the stage of economic transformation and upgrading, the application of personnel requirements have been improved accordingly, it is necessary to pay attention to professional knowledge and comprehensive ability level, but also pay attention to the quality of talent, the serious and responsible work attitude, hard work and determination enthusiasm, teamwork and personal good conduct. According to the 2015 undergraduate graduate survey results showed that its turnover rate of up to $34 \%$ within six months, and the main reason for the resignation is the job or salary can't achieve the desired effect, it can be said that the low pay is the main reason. According to the graduates within three years of "job hopping" to analyze the situation, in 2012, undergraduate within three years has an average of 1.9 employers work, which reflects the contemporary graduation

Utilitarian, Short-Sighted of the School Functions. Social service, scientific and technological innovation, scientific research is the most important basic school functions. However, in terms of the current situation of running a school, most of the applied undergraduate functions are utilitarianized and short-sighted, which seriously restricts the infiltration and development of the supply-side reform of the applied universities. According to the existing national policy system, is divided according to a series of grades. First, the central subordinate "985" "211" institutions, followed by the provincial and municipal institutions, and finally for the local direct institutions. The state generally in accordance with this standard in the capital investment, school construction, student protection and other aspects of differentiated treatment, and with the status of the school widened, resulting in a serious imbalance in the allocation of educational resources. In the education funding, teachers, opportunities for development of higher levels of institutions to get the resources to gain more advantages, and local universities, especially the application universities as the identity of the glass door and not a fair opportunity for development. Even if the same belong to local universities, the provincial education management department will still be divided into provincial key institutions and non-key institutions, even with the undergraduate education colleges and universities due to "university" and "college" also have significant differences in all aspects of treatment. Institutions of the Matthew effect between them become more obvious, inevitably lead to college education utilitarian, greedy desire for the full run of school thinking, blindly opened a number of schools do not meet the actual situation of professional. Resulting in thin construction of institutions, professional without characteristics, training students in the employment process is not competitive, wasting a lot of school resources. Limit their own supply capacity to improve, mainly for the following two aspects: First, the application of college social service positioning fuzzy. Some of the applied undergraduate departments provide their own social services entry point is not clear, can't find the positioning of social and economic development, the specific service area is not in-depth understanding, and thus can't be targeted for regional economic and social development of effective school way to open up new ways of teaching. Second, scientific and technological innovation and scientific research mechanism is not perfect, the results of conversion efficiency is not high. Although the number of patent applications and licenses in applied universities is high, but the conversion rate is very low. In 2015, China's investment in research projects is comparable to that of moderately developed countries, and its level is among the best in developing countries , And now China's undergraduate application-oriented institutions in the research results have always 
been inclined to academic level rather than technology to create and invent, ignoring the transformation of scientific and technological achievements of the economic and social impact, resulting in scientific research predicts and analysis deviated from the Central track, a lot of technological innovation can't be out of the laboratory, resulting in huge resources and economic waste.

\section{The Important Measures of the Reform Application of Universities Supply Side}

Modern application-oriented universities face the problem of supply and demand dislocation, positioning and other fuzzy reform. Application-oriented undergraduate in order to stabilize the development and adjustment of social and business relationship between supply and demand, they must focus on the university mission, identify the school positioning. To adapt to the development side of the supply side to change the general trend, to seize the supply side of the reform brought about by the development opportunities, based on the purpose of reform and service social and economic development, highlighting the characteristics of applied universities to achieve changes in the characteristics of the development.

The Key Point of the Reform of the Supply Side of the Applied Universities. To seek new development, supply-side reforms must be implemented. So what is the key point of the reform of the supply side of the applied university? There is no doubt that it is necessary to adjust the current educational structure, through reasonable adjustment, then the change in demand flexibility and adaptability is bound to be enhanced, thereby increasing total factor productivity. Therefore, in line with the reform and development, a clear key is essential thing to seek new development.

Social demand and economic development direction are the key points of the reform of the applied colleges and universities, and also play a role in promoting the development prospect. At present, it is precisely that the imbalance between the applied universities and the social supply and demand and the economic development direction. Problems should be solved in the development of colleges and universities. Therefore, the application of colleges and universities must be a comprehensive understanding of social needs and economic development direction to optimize the professional settings, adjust the supply structure as a way to enrich the teaching resources, improve the teaching environment, innovate the service model, to create more choices for students, as much as possible to improve the quality and efficiency of personnel training, in promoting the individual development of students at the same time, make it more close to the type of social demand for talent, and enhance the application universities in the supply of flexibility and adaptability.

It is not difficult to see that the development depends essentially on the supply side, and that every time the industry changes or the technological revolute, the productive forces will be greatly improved, thus creating new and powerful supply capacity. General Secretary Xi Jinping has repeatedly stressed: "to promote the supply-side of the reform, we must firmly establish the concept of innovation and development, to promote new technologies, new industries, new industry to flourish for the sustained and healthy development of the economy to provide a steady endogenous motivation." The application universities to implement the supply side of the reform of the most direct and powerful driving force, and institutions should give full play to the advantages, professional advantages and technological advantages, innovate educational philosophy, improve the teaching system, and as a basis to promote scientific and technological innovation, improve the quality of service, to adapt to economic development and social needs of the comprehensive strength, and ultimately provide the application universities with comprehensive reform supply side. Application-oriented universities should first set their own school orientation, school objectives, take the initiative and local social development, economic development in line with the direction of a symbiotic win-win relationship to promote their own development. According to the needs of local talent, they should actively adjust the school professional courses, teaching direction, scientific research projects to support the local economic and social development of the necessary talent supply and intellectual support. Innovative efforts should be done in accordance with the local economic development level and social needs, adjust the implementation of innovation and development strategies, and continuously improve the local economic and social development 
capacity and level

Take Social Services and Scientific and Technological Innovation as the Guide, Improve the Level of Social and Economic Development. Applied colleges have their own typical characteristics, is to serve the local society and promote local economic construction. Based on this feature, the application universities should effectively use their own advantages, for local regional development, planning, talent needs and technology research and development to provide strong support to maximize the local economic development.

Application-oriented universities must take the social service and scientific and technological innovation as the guide, to meet the needs of local economic construction for the purpose of coordinating the supply of personnel training as the main line to build school development blueprint to accelerate the school from academic research to science and technology application-oriented change. Through the school-enterprise cooperation and other ways to jointly study innovative teaching methods, strengthen the student industry technology research and development capabilities and practice accumulation, to achieve regional economy, social needs, talent supply the three aspects of collaborative development. In addition, the application universities should also take the local economic development planning and industrial transformation and upgrading as a research focus, and actively docking the local industry and the future direction of development, so that provide strong talent supply support for a local industrial development and technological innovation.

The application of scientific research road should adhere to the characteristics and localization, the use of the school's local advantages in talent support, give strong support to technical support and management decision-making. The school can also combine the local area in the industrial needs, technical difficulties and development direction when required, the relevant content into the teaching area, and the technical problems encountered in the development of enterprises and difficult to focus on management, and vigorously build technological innovation platform for enterprises to provide more innovative talents. To improve the quality of social services, applied universities must achieve the local emerging industries, traditional industries, pillar industries and transition industry technology docking, from the perspective of strategic development personnel training services.

And local enterprises build a perfect social service system, not only pay attention to school and enterprise integration, production and education, but also focus on solving technical difficulties in the industry, breaking the technical bottleneck. Therefore, the application-oriented universities should make full use of the advantages of local enterprises' technical resources and innovative resources, create a resource sharing platform, build a development linkage pattern, promote the development of new technologies and high-quality talent supply training mode with enterprise development and social demand as the core, able to adapt to the traditional industrial restructuring, the rise of emerging industries, accelerate the pace of development of pillar industries of modern application-oriented colleges and universities to achieve the ultimate goal of education supply side reform.

Application-oriented universities should realize that the cooperation of small and medium-sized enterprises plays an important role in the development of schools. Encourage the broad masses of teachers to actively participate in their own scientific and technological achievements, intellectual resources and enterprise technology needs, economic development will be combined to give full play to the economic benefits of intellectual results. It is necessary to change the existing evaluation system of teachers, from the emphasis on vertical topics of the declaration, title and awards, ignoring the research and transformation of horizontal issues, to the vertical issues and horizontal issues on the same important position. Encourage the majority of teachers to achieve the industrialization of scientific research results of industrialization, to encourage teachers in accordance with the production of small and medium enterprises encountered in the practical problems, the establishment of scientific research projects, carry out scientific research work. And gradually improve the income of teachers, reflecting the intelligence, science and technology is the actual embodiment of the first productive forces. 
The purpose of the reform of the supply-side colleges is that the supply of surplus and the quality of talents is too low, the supply structure is adjusted, the professional structure is optimized and upgraded, and the supply relationship with the social demand and economic development is coordinated. Therefore, the application universities should continue to optimize the professional settings, improve the quality of supply talent, open up talent training channels, build school-enterprise cooperation platform, sharing school technology resources, focus on building technology talents and technological innovation talents to meet the future industry, and promote the development of institutions and their own social and economic development.

\section{References}

[1] Chunhua Qiao. Journal of supply side reform and development of higher education[J]. Huaibei Normal University(PHILOSOPHY AND SOCIAL SCIENCES EDITION).2016.02 .

[2] Yuhua Li. The supply of higher education in China on the reform of the education[J]. 2016.05 .

[3] "double top" under the background of the construction of local colleges and universities and the Countermeasures of the development Ling Zhang,Hongyu Li[J].(Journal of ChifengUniversity Chinese philosophy and Social Sciences Edition).2016.11.25 .

[4] Yan Ma.Strengthen the supply side concept to the integration of production and education[J]. higher education China principle.2016.10.

[5] speed up scientific and technological innovation to promote the supply side structural reform Qiuli [J].Chen Provincial Science and technology department director of the Fujian daily - party secretary 2016.04.11.

[6] Zhongjiang Wu.Chengliang Huang [J]. higher engineering education research.2014.02

[7] Zhanhua Fang training content the application and development of applied undergraduate talents; painting. Driven by innovation of Applied University supply side structural reform[N]. Guangming Daily.2016.06.22.

[8] Zhaoting Yang.Reflections on the supply side reform of applied talents.[N]. China Education Daily.2016.04.18.

[9] Yunsheng Liu. Supply side structure reform: how to do education?[J]. education development research.2016.03.

Author brief introduction: Lianpeng Wang, Male, Han nationality, Doctor, assistant professor in Marxism School of Northwestern University, his research direction is law and higher education. 